\title{
Neurovascular Protection by Ischemic Tolerance: Role of Nitric Oxide and Reactive Oxygen Species
}

\author{
Alexander Kunz, ${ }^{\star}$ Laibaik Park, ${ }^{*}$ Takato Abe, Eduardo F. Gallo, Josef Anrather, Ping Zhou, and Costantino Iadecola \\ Division of Neurobiology, Weill-Cornell Medical College, KB-410, New York, New York 10021
}

Cerebral ischemic preconditioning or tolerance is a powerful neuroprotective phenomenon by which a sublethal injurious stimulus renders the brain resistant to a subsequent damaging ischemic insult. We used lipopolysaccharide (LPS) as a preconditioning stimulus in a mouse model of middle cerebral artery occlusion (MCA0) to examine whether improvements in cerebrovascular function contribute to the protective effect. Administration of LPS $24 \mathrm{~h}$ before MCAO reduced the infarct by $68 \%$ and improved ischemic cerebral blood flow (CBF) by $114 \%$ in brain areas spared from infarction. In addition, LPS prevented the dysfunction in cerebrovascular regulation induced by MCA0, as demonstrated by normalization of the increase in CBF produced by neural activity, hypercapnia, or by the endotheliumdependent vasodilator acetylcholine. These beneficial effects of LPS were not observed in mice lacking inducible nitric oxide synthase (iNOS) or the nox2 subunit of the superoxide-producing enzyme NADPH oxidase. LPS increased reactive oxygen species and the peroxynitrite marker 3-nitrotyrosine in wild-type mice but not in nox2 nulls. The peroxynitrite decomposition catalyst 5,10,15, 20tetrakis(4-sulfonatophenyl)porphyrinato iron (III) attenuated LPS-induced nitration and counteracted the beneficial effects of LPS on infarct volume, ischemic CBF, and vascular reactivity. Thus, LPS preserves neurovascular function and ameliorates CBF in regions of the ischemic territory at risk for infarction. This effect is mediated by peroxynitrite formed from iNOS-derived NO and nox2-derived superoxide. The data indicate that preservation of cerebrovascular function is an essential component of ischemic tolerance and suggest that combining neuroprotection and vasoprotection may be a valuable strategy for treating ischemic brain injury.

Key words: peroxynitrite; mice; ischemic preconditioning; hydroethidine; 3-nitrotyrosine; NADPH oxidase; focal cerebral ischemia; cranial window

\section{Introduction}

Cerebral ischemic tolerance or preconditioning is an endogenous neuroprotective phenomenon in which a noxious stimulus applied to the brain confers transient protection against a subsequent injurious ischemic insult (Gidday, 2006). Ischemic tolerance consists of an early phase that occurs within minutes after induction, followed by a delayed phase that develops many hours or even days later (Kirino, 2002). Delayed preconditioning has generated much interest because it produces a potent neuroprotection whose mechanisms may suggest new treatments for ischemic stroke (Dawson, 2002; Gidday, 2006).

Many studies have addressed the mechanisms by which preconditioning stimuli, such as transient cerebral ischemia or the proinflammatory mediator lipopolysaccharide (LPS), protect the brain from injury [for review, see Kirino (2002), Dirnagl et al. (2003), and Gidday (2006)]. These investigations have established that ischemic tolerance is associated with genetic, bio-

Received April 12, 2007; revised May 12, 2007; accepted May 18, 2007.

This work was supported by National Institutes of Health (NIH) Grants NS34179 and NS35806 (C.I.) and by the Deutsche Forschungsgemeinschaft (KU 1990/1-1; A.K.). C.I. is the recipient of a Javits award from NIH-National Institute of Neurological Disorders and Stroke. We thank Dr. Carrie Drake for her comments on this manuscript.

${ }^{*}$ A.K. and L.P. contributed equally to this work.

Correspondence should be addressed to Dr. Costantino ladecola, Division of Neurobiology, Weill-Cornell Medical College, 411 East 69th Street, KB-410, New York, NY 10021. E-mail: coi2001@med.cornell.edu.

DOI:10.1523/JNEUROSCI.1645-07.2007

Copyright $\odot 2007$ Society for Neuroscience $\quad$ 0270-6474/07/277083-11\$15.00/0 chemical, and neurophysiological changes in neurons and glia that render the brain more resistant to ischemia. However, it has also been observed that tolerance-inducing stimuli improve microvascular perfusion or cerebral blood flow (CBF) in the postischemic brain (Dawson et al., 1999; Furuya et al., 2005; Hoyte et al., 2006; Nakamura et al., 2006; Zhao and Nowak, 2006). Although these studies have suggested that preconditioning protects cerebral blood vessels from the vasoparalysis induced by cerebral ischemia, the effects of preconditioning on cerebrovascular function and the specific contribution of vascular factors to the protection have not been determined.

Inducible nitric oxide synthase (iNOS) is essential for the development of tolerance in several models. Preconditioning stimuli such as ischemia, LPS, or isoflurane anesthesia upregulate iNOS expression, whereas pharmacological inhibition or genetic inactivation of iNOS prevents the tolerance to ischemia or excitotoxicity (Kapinya et al., 2002; Cho et al., 2005b; Kawano et al., 2007). The mechanisms by which iNOS-derived NO contributes to the protection remain to be established. We have recently found that NADPH oxidase, an important source of reactive oxygen species (ROS) in brain and blood vessels, is involved in the tolerance to excitotoxic brain lesions (Kawano et al., 2007). The observation that preconditioning requires both iNOS-derived $\mathrm{NO}$ and ROS suggests the involvement of peroxynitrite (Kawano et al., 2007), the reaction product of NO with the free radical superoxide (Pacher et al., 2007). However, it is not known 
whether NO and superoxide are also critical for ischemic tolerance or whether improvements in CBF play a role in the protection.

Therefore, we examined the role of vascular factors in the protective effect of LPS in a mouse model of middle cerebral artery (MCA) occlusion. We found that LPS improves CBF in regions of the ischemic territory spared from infarction, an effect associated with a dramatic improvement in the vascular dysregulation induced by cerebral ischemia. Such vasoprotective effect of LPS is mediated by peroxynitrite formed from iNOS-derived NO and NADPH oxidase-derived superoxide. Thus, preconditioning, in addition to its effects on neurons and glia, also protects cerebral blood vessels from cerebral ischemia. The findings suggest that the combination of neuroprotective and vasoprotective approaches may provide new powerful therapeutic strategies for ischemic stroke.

\section{Materials and Methods \\ Animals}

All experimental procedures were approved by the Institutional Animal Care and Use Committee of Weill-Cornell Medical College. Experiments were performed in 2- to 3-month-old male mice lacking iNOS (MacMicking et al., 1995) or the nox2 subunit of NADPH oxidase (Pollock et al., 1995). Mice were obtained from in-house colonies (Park et al., 2004, 2005) and were congenic with the C57BL/6 strain. Therefore, C57BL/6 mice were used as wild-type controls.

\section{LPS administration}

Salmonella typhimurium LPS (0.5 mg/kg; lot number 054K4010; SigmaAldrich, St. Louis, MO) or vehicle (saline) was administered intraperitoneally, and mice were returned to their cages (Cho et al., 2005b; Kawano et al., 2007). This dose of LPS produces a small reduction in rectal temperature, but the effect is transient and does not account for the neuroprotection (Kawano et al., 2007). Mice were subjected to MCA occlusion $24 \mathrm{~h}$ after LPS administration.

\section{MCA occlusion and measurement of ischemic cerebral blood flow} Procedures for MCA occlusion have been published previously (Park et al., 2004; Cho et al., 2005a; Kunz et al., 2007) and are only summarized here. Mice were anesthetized with a mixture of isoflurane $(1.5-2 \%)$, oxygen, and nitrogen. A fiber-optic probe was glued to the parietal bone ( $2 \mathrm{~mm}$ posterior and $5 \mathrm{~mm}$ lateral to bregma) and connected to a laserDoppler flowmeter (Periflux System 5000; Perimed, Järfälla, Sweden) for continuous monitoring of $\mathrm{CBF}$ in the center of the ischemic territory. In some experiments, the flow probe was placed $2 \mathrm{~mm}$ lateral to bregma to monitor $\mathrm{CBF}$ at the periphery of the ischemic territory. This site was selected in preliminary experiments to overlie the neocortex rescued from infarction by LPS preconditioning (Fig. 1A) [for methods, see Zhang et al. (1994)]. For MCA occlusion, a heat-blunted monofilament surgical suture (6-0) was inserted into the exposed external carotid artery, advanced into the internal carotid artery, and wedged into the circle of Willis to obstruct the origin of the MCA. The filament was left in place for $25 \mathrm{~min}$ and then withdrawn. Only animals that exhibited a reduction in $\mathrm{CBF}$ of $>85 \%$ during MCA occlusion and in which CBF recovered by $>80 \%$ after $10 \mathrm{~min}$ of reperfusion were included in the study (Cho et al., 2005). This procedure leads to reproducible infarcts similar in size and distribution to those reported by others using transient MCA occlusion of comparable duration (Boutin et al., 2001; Plesnila et al., 2001; Borsello et al., 2003). Rectal temperature was monitored and kept constant $\left(37.0 \pm 0.5^{\circ} \mathrm{C}\right)$ during the surgical procedure and in the recovery period until the animals regained full consciousness.

\section{Infarct volume measurement}

Mice were killed $72 \mathrm{~h}$ after ischemia, and their brains were removed, frozen, and sectioned (thickness, $30 \mu \mathrm{m}$ ) in a cryostat. Brain sections were collected at $600 \mu \mathrm{m}$ intervals and stained with thionine. Infarct volume was determined using an image analyzer (MCID; Imaging Research, St. Catharines, Ontario, Canada) (Cho et al., 2005a; Kunz et al.,
A

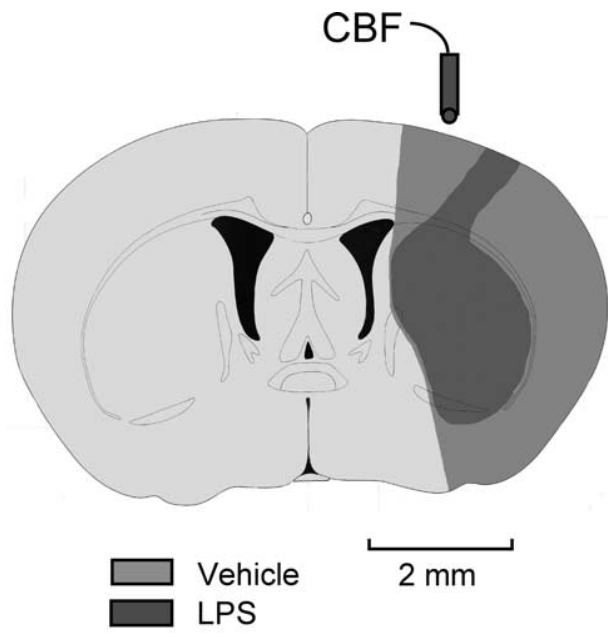

B

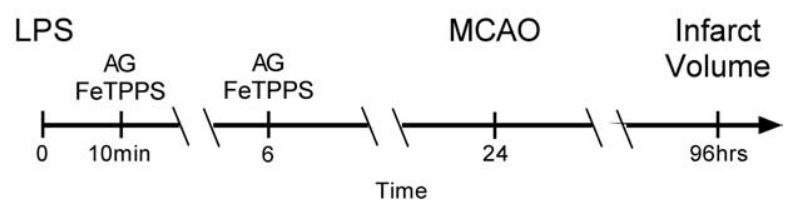

C

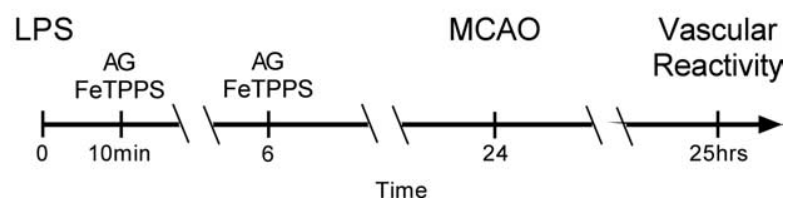

Figure 1. A, Location of the laser-Doppler probe relative to the composite regional distribution of the infarct at the level of bregma in mice treated with vehicle or LPS ( $n=5$ per group). $B$, Protocol for experiments in which infarct volume was measured. LPS was administered at time 0 , the MCA was occluded $24 \mathrm{~h}$ later, and infarct volume was determined $72 \mathrm{~h}$ after MCA occlusion (MCA0). AG or FeTPPS was administered $10 \mathrm{~min}$ and $6 \mathrm{~h}$ after LPS. C, Protocol for experiments in which postischemic vascular reactivity was assessed. Immediately after reperfusion, mice were instrumented with a cranial window for CBF recording with controlled arterial pressure and blood gases.

2007). To eliminate the contribution of postischemic edema to the volume of injury, values were corrected for swelling according to the method of Lin et al. (1993) as described previously (Zhang and Iadecola, 1994).

\section{Postischemic cerebrovascular regulation}

Procedures for testing cerebrovascular regulation in mice have been described previously (Park et al., 2005; Girouard et al., 2007). Briefly, under isoflurane anesthesia, the femoral artery was cannulated for recording of arterial pressure and collection of blood samples. Mice were then intubated and artificially ventilated with an oxygen-nitrogen mixture adjusted to provide an arterial $\mathrm{pO}_{2}$ of $120-140 \mathrm{mmHg}$ (supplemental Table 1 , available at www.jneurosci.org as supplemental material). Rectal temperature was maintained at $37^{\circ} \mathrm{C}$ using a thermostatically controlled rectal probe connected to a heating device. After surgery, isoflurane was gradually discontinued, and anesthesia was maintained with urethane (750 mg/kg, i.p.; Sigma-Aldrich) and $\alpha$-chloralose $(50 \mathrm{mg} / \mathrm{kg}$, i.p.; Sigma-Aldrich). The stability of the level of anesthesia was checked by testing corneal reflexes and motor responses to tail pinch. The somatosensory cortex was exposed through a small craniotomy $(2 \times 2 \mathrm{~mm})$. The dura was removed, and the site was superfused with a modified Ringer's solution $\left(37^{\circ} \mathrm{C}\right.$; $\left.\mathrm{pH} 7.3-7.4\right)$ (for composition, see Iadecola, 1992). CBF was continuously monitored at the site of superfusion with a laserDoppler probe (Vasamedic, St. Paul, MN) positioned stereotaxically on the somatosensory cortex, a region supplied by the MCA and rescued from infarction by LPS. CBF changes were expressed as percentage in- 
crease relative to the resting level. Zero values for CBF were obtained after the heart was stopped by an overdose of isoflurane at the end of the experiment. To study the increase in CBF produced by neural activity (functional hyperemia), the somatosensory cortex was activated by gently stroking the contralateral whiskers with a cotton-tipped applicator for $60 \mathrm{~s}$. Endothelium-dependent vasodilation was tested by topical superfusion of acetylcholine (ACh; $10 \mu \mathrm{m}$; Sigma-Aldrich) for 3-5 min, and the $\mathrm{CBF}$ increase was recorded. The increase in CBF produced by hypercapnia was examined by introducing $5 \% \mathrm{CO}_{2}$ in the ventilator to increase arterial $\mathrm{pCO}_{2}$ to $50-60 \mathrm{mmHg}$ (supplemental Table 1 , available at www.jneurosci.org as supplemental material). Once a stable increase in $\mathrm{CBF}$ was obtained, $\mathrm{pCO}_{2}$ was returned to normocapnia. The CBF response to adenosine ( $400 \mu \mathrm{m}$; Sigma-Aldrich), an agent that produces vasodilation by acting directly on vascular smooth muscles (Phillis, 2004), was also tested.

\section{Quantification of ROS production and 3-nitrotyrosine immunoreactivity}

ROS production was determined using in vivo hydroethidine microfluorography (Kondo et al., 1997), as described previously (Cho et al., 2005a; Kunz et al., 2007). Hydroethidine is a cell-permeant dye that is oxidized to ethidium and related products by superoxide (Robinson et al., 2006). Ethidium is trapped intracellularly by intercalating with DNA (Rothe and Valet, 1990). The fluorescence signal attributable to hydroethidine oxidation products reflects cumulative ROS production during the period between administration of hydroethidine and killing the animal. Hydroethidine (10 mg/kg; Invitrogen, Carlsbad, CA) was injected into the jugular vein in mice under isoflurane anesthesia $1 \mathrm{~h}$ before they were killed. Brains were removed, frozen, sectioned in a cryostat (thickness, $20 \mu \mathrm{m}$ ), and collected at $600 \mu \mathrm{m}$ intervals (Kunz et al., 2007).

3-Nitrotyrosine (3-NT) was used as a marker of peroxynitrite-induced nitration (Pacher et al., 2007). Mice were perfused transcardially with heparinized saline, and their brains were removed and frozen. Brain sections (thickness, $14 \mu \mathrm{m}$ ) were cut through the parietal cortex and collected at $100 \mu \mathrm{m}$ intervals. To assure uniformity of the immunolabel, sections from controls and experimental groups were processed together. Sections were postfixed in ethanol and incubated with a 3-NT antibody (1:200; Millipore, Billerica, MA), followed by a FITC-conjugated secondary antibody (1:200; Invitrogen). The specificity of the 3-NT stain was tested as described previously (Forster et al., 1999).

Procedures for quantification of the fluorescence signal have been described previously (Cho et al., 2005a; Girouard et al., 2007; Kunz et al., 2007). Sections were analyzed with a Nikon (Melville, NY) E800 fluorescence microscope equipped with filter sets (Chroma Technology, Rockingham, VT) customized for detection of hydroethidine oxidation products (for ROS production) or FITC (for 3-NT immunoreactivity). Images were acquired by a computer-controlled digital monochrome camera (Coolsnap; Roper Scientific, Trenton, NJ) attached to the microscope. The analysis of ROS or 3-NT immunoreactivity was performed in a blinded manner using IPLab software (Scanalytics, Fairfax, VA) (Cho et al., 2005a; Kunz et al., 2007). The intensity of the ROS or 3-NT signal was analyzed in brain parenchyma and cortical blood vessels identified according to morphological criteria (i.e., surface pial and penetrating cortical vessels) and confirmed by double label with the endothelial marker CD31 (Girouard et al., 2007). When vessels were analyzed, at least 10 vessels per animal were studied. Fluorescence intensities were divided by the total number of pixels analyzed, averaged, and expressed as relative fluorescence units (Cho et al., 2005a; Girouard et al., 2007; Kunz et al., 2007).

\section{Double-label immunohistochemistry}

For identification of the cell types producing ROS, mice treated with hydroethidine were anesthetized with sodium pentobarbital $(120 \mathrm{mg} / \mathrm{kg})$ and perfused transcardially with $4 \%$ paraformaldehyde. Brains were removed, frozen, and sectioned through the parietal cortex. Brain sections were incubated with antibodies against the neuronal marker NeuN (1: 100; Millipore), the endothelial cell marker CD31 (1:100; BD Biosciences, San Diego, CA), or the astrocytic marker glial fibrillary acidic protein (GFAP) (1:1000; Sigma-Aldrich). Sections were then incubated with cyanine dye (Cy5)-conjugated secondary antibodies (Jackson ImmunoResearch, West Grove, PA). For identification of the cell types expressing 3-NT, frozen sections were first processed for 3-NT immunocytochemistry, followed by incubation with anti-NeuN, anti-CD31, or anti-GFAP antibodies, and, subsequently, Cy5-conjugated secondary antibodies. The specificity of the immunolabel was assessed by omitting the primary antibodies or by preadsorption with the antigen (Forster et al., 1999). Images of double-labeled neocortex were sequentially acquired using a Leica (Mannheim, Germany) TCS SP5 confocal laserscanning microscope. ROS and 3-NT signals were pseudocolored red, whereas Cy5 signals were pseudocolored green.

\section{Experimental protocol}

Effect of LPS preconditioning on infarct volume. As illustrated in Figure $1 B$, LPS or vehicle (saline) was injected in wild-type, iNOS, or nox2-null mice, and the MCA was transiently occluded $24 \mathrm{~h}$ later. Infarct volume was measured $72 \mathrm{~h}$ after induction of ischemia. In some studies, the iNOS inhibitor aminoguanidine (AG; $400 \mathrm{mg} / \mathrm{kg}$, i.p.; Sigma-Aldrich) (Park et al., 2004), the peroxynitrite decomposition catalyst 5,10,15, 20tetrakis(4-sulfonatophenyl)porphyrinato iron (III) (FeTPPS; $20 \mathrm{mg} / \mathrm{kg}$, i.v.; EMD Biosciences, San Diego, CA) (Misko et al., 1998; Salvemini et al., 1998; Li et al., 2005) or vehicle (saline) was administered $10 \mathrm{~min}$ and $6 \mathrm{~h}$ after LPS. AG administration according to this protocol abolishes LPS-induced ischemic tolerance to focal cerebral ischemia (Cho et al., $2005 \mathrm{~b}$ ) and attenuates the accumulation of NO reaction products (NOx) in brain after LPS administration (supplemental Fig. 1, available at www. jneurosci.org as supplemental material). The administration protocol for FeTPPS was demonstrated to block LPS-induced 3-NT immunoreactivity (see Results). In some experiments, the neuronal nitric oxide synthase (nNOS) inhibitor 7-nitroindazole (7-NI; $25 \mathrm{mg} / \mathrm{kg}$, i.p.; Cayman Chemical, Ann Arbor, MI) or vehicle (DMSO) was administered $1 \mathrm{~h}$ before MCA occlusion (Park et al., 2004), and infarct volume was measured $72 \mathrm{~h}$ after MCA occlusion.

Effect of LPS preconditioning on postischemic cerebrovascular reactivity. As illustrated in Figure $1 C$, mice were treated with vehicle, AG, or FeTPPS $10 \mathrm{~min}$ and $6 \mathrm{~h}$ after LPS, and the MCA was occluded $24 \mathrm{~h}$ later. Immediately after the start of reperfusion, mice were instrumented for monitoring of CBF in the ischemic cortex (see above, Postischemic cerebrovascular regulation). Approximately $1 \mathrm{~h}$ after reperfusion, when resting CBF was stable, the increase in CBF produced by functional hyperemia (whisker stimulation), ACh, adenosine, or hypercapnia was tested. The mean arterial pressure (MAP) and blood gases for these mice are presented in supplemental Table 1 (available at www.jneurosci.org as supplemental material). MCA occlusion resulted in a reduction in MAP, but such hypotension occurred in all groups and, as such, it is unlikely to contribute to the difference in vascular reactivity observed between mice receiving vehicle, LPS, or LPS plus AG.

Effect of LPS on ROS and 3-NT immunoreactivity. To determine the time course of ROS and 3-NT, brains were processed for ROS production or 3 -NT immunoreactivity $1,2,4,8,12$, and $24 \mathrm{~h}$ after LPS. Analyses focused on the parietal cortex, the region that is rescued from infarction by preconditioning and in which ischemic $\mathrm{CBF}$ and postischemic vascular reactivity were studied. For ROS production, mice were injected with hydroethidine $1 \mathrm{~h}$ before they were killed. In experiments in which iNOS or nox2-null mice were used, ROS production was examined 2 and $12 \mathrm{~h}$ after LPS, and 3-NT immunoreactivity was examined $24 \mathrm{~h}$ after LPS. These time points were selected based on the time course of ROS and 3-NT immunoreactivity after LPS administration (see Results). Doublelabel experiments for identification of the cell types producing ROS and exhibiting 3-NT immunoreactivity were performed, respectively, 2 and $24 \mathrm{~h}$ after LPS. In some experiments, FeTPPS was injected $10 \mathrm{~min}$ and $6 \mathrm{~h}$ after LPS, and 3-NT immunoreactivity was assessed at $24 \mathrm{~h}$. To induce ROS production in astrocytes, mice were treated with topical neocortical application of the superoxide dismutase (SOD) inhibitor diethyldithiocarbamate (DDC; $10 \mathrm{~mm}$; Sigma-Aldrich), and their brains were processed for double labeling for ROS and GFAP.

\section{Statistical analysis}

Data are presented as mean \pm SEM. Comparisons between two groups were statistically evaluated by the Student's $t$ test. Multiple comparisons 
were evaluated by ANOVA followed by Newman-Keuls multiplecomparison test. The temporal profiles of LPS-induced ROS and 3-NT were analyzed by ANOVA followed by Dunnett's test. Differences were considered significant at $p<0.05$.

\section{Results}

LPS improves ischemic $\mathrm{CBF}$ and reduces infarct volume through iNOS-derived NO

First, we sought to determine whether LPS preconditioning is associated with an improvement of ischemic CBF. LPS administration resulted in a $68 \%$ reduction in infarct volume (Fig. $2 \mathrm{~A}$ ). The protective effect was associated with a marked CBF improvement in the region of the ischemic territory that was spared from infarction (Fig. 2B). At reperfusion, CBF was lower in LPStreated mice than in vehicle-treated controls (Fig. $2 \mathrm{~B}$ ), but this is not surprising because the changes in $\mathrm{CBF}$ at reperfusion do not correlate well with the outcome of the ischemic insult (Marchal et al., 1999). Administration of the iNOS inhibitor AG blocked the effect of LPS on infarct volume and abolished the improvement in ischemic CBF (Fig. 2A,B). AG alone did not influence infarct volume or ischemic $\mathrm{CBF}$ (Fig. $2 A, B$ ). In agreement with the $\mathrm{AG}$ results, LPS did not reduce infarct volume (vehicle, $25 \pm 5 \mathrm{~mm}^{3}$; LPS, $28 \pm 2 \mathrm{~mm}^{3} ; p>0.05 ; n=5$ per group) or improve ischemic CBF in iNOS-null mice (Fig. 2C). However, administration of the nNOS inhibitor 7-NI to iNOS-null mice reduced infarct volume by $46 \%$ (vehicle, $31 \pm 4 \mathrm{~mm}^{3}$; 7-NI, $17 \pm 1 \mathrm{~mm}^{3} ; p<$ $0.05 ; n=6$ per group), ruling out the possibility that the lack of effect of LPS in iNOS-null mice was attributable to an already maximally reduced infarct.

LPS improves postischemic cerebrovascular dysregulation via iNOS-derived NO

The findings presented above suggest that an improvement in ischemic CBF may play a role in the protective effect of LPS. Cerebral ischemia impairs the vasodilatory capacity of cerebral blood vessels and limits their ability to divert blood flow from normally perfused regions to the ischemic territory (collateral flow) (Date and Hossmann, 1984; Mayhan et al., 1988). The improvement in ischemic CBF raises the possibility that LPS ameliorates the vascular dysregulation induced by cerebral ischemia and promotes collateral flow. To test this hypothesis, we examined postischemic vascular reactivity in mice treated with vehicle or LPS. In vehicle-treated mice, focal ischemia resulted in a marked attenuation $(p<0.05)$ of the CBF increases induced by whisker stimulation $(-57 \%)$, ACh $(-59 \%)$, and hypercapnia $(-36 \%)$, but not adenosine $(p>0.05)$ (Fig. 3). In LPS-treated mice, postischemic vascular reactivity was preserved and was comparable with that of nonischemic controls $(p>0.05)$. Such vascular improvement by LPS was abolished by AG and was not observed in iNOS-null mice (Figs. 3, 4). These results indicate that LPS improves the cerebrovascular dysfunction induced by cerebral ischemia and that the effect depends on iNOS.

\section{LPS increases vascular ROS production through}

\section{NADPH oxidase}

ROS have been implicated in the development of ischemic tolerance (Liu et al., 2005). Therefore, we investigated whether ROS participate in the tolerance to cerebral ischemia induced by LPS. First, we used hydroethidine microfluorography to examine whether LPS induces ROS production in cerebral cortex. LPS increased the ROS signal at 2 and $12 \mathrm{~h}$ after LPS, and the increase subsided at $24 \mathrm{~h}$ (Fig. 5C). The ROS increase was observed in cells positive for the neuronal marker NeuN or the endothelial marker
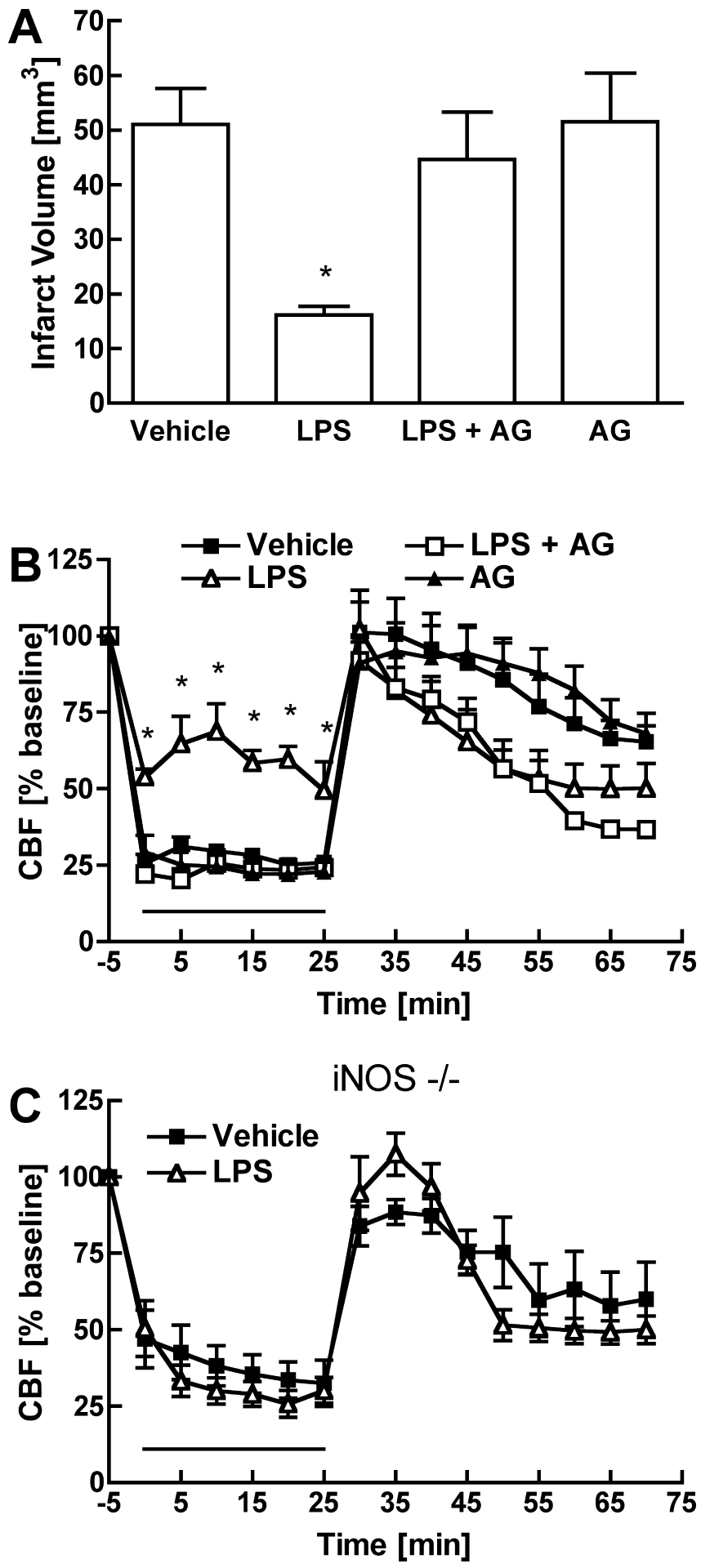

Figure 2. $\quad \boldsymbol{A}$, Effect of LPS on infarct volume with or without pretreatment with AG. $\boldsymbol{B}$, Intraischemic CBF in the groups of mice presented in $A$. C, Effect of LPS on intraischemic CBF in iNOS-null mice. $B, C$, The black line below the CBF curves indicates the MCA occlusion period. ${ }^{*} p<0.05$ compared with vehicle, LPS plus AG, and AG; ANOVA and Newman-Keuls test; $n=$ $5-7$ per group.

CD31, but not for the astroglial marker GFAP (Fig. 5A, $B$ ). The lack of signal in astrocytes was not an artifact of the method used to assess ROS production, because cortical superfusion with the SOD inhibitor DDC induced detectable oxidative stress in these cells (Fig. $5 B j-B l, B m-B o$ ). NADPH oxidase has emerged as an important source of ROS in neurons and cerebral blood vessels 

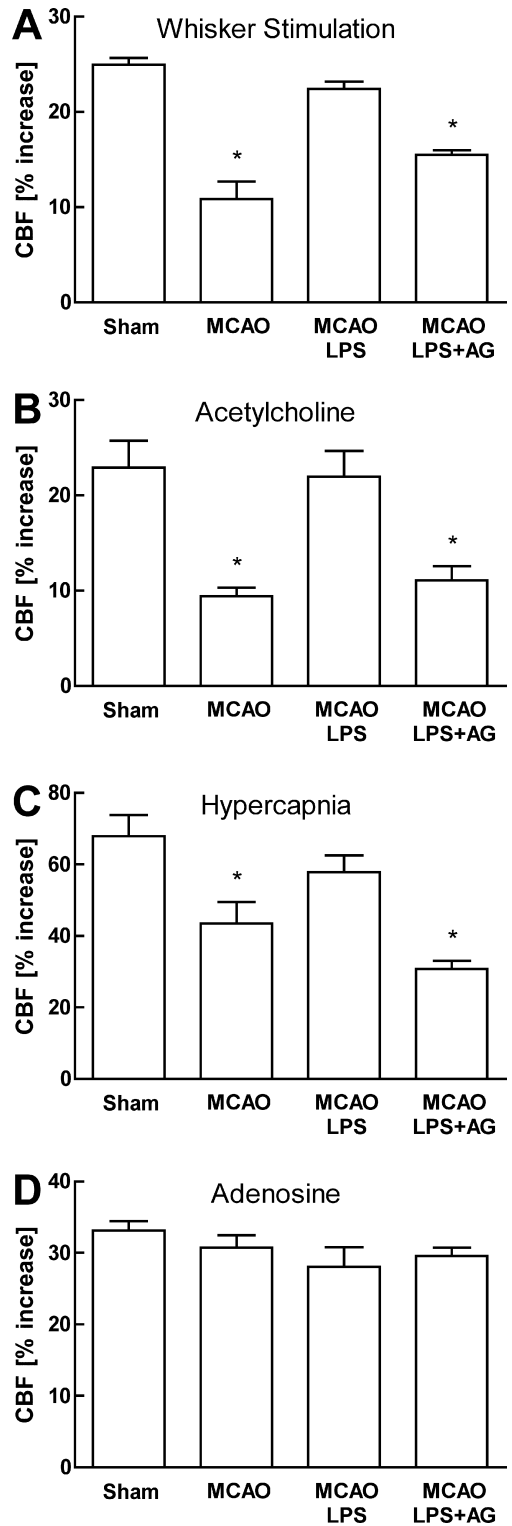

Figure 3. $A-D$, Effect of MCA occlusion (MCAO) on the increase in $C B F$ produced by whisker stimulation $(\boldsymbol{A})$, topical superfusion with acetylcholine $(10 \mu \mathrm{m} ; \boldsymbol{B})$, hypercapnia $\left(\mathrm{pCO}_{2}=\right.$ $50-60 \mathrm{mmHg} ; \boldsymbol{C}$, or topical superfusion of adenosine $(400 \mu \mathrm{m} ; \boldsymbol{D})$ with or without LPS or LPS plus AG. ${ }^{*} p<0.05$ compared with sham and MCAO plus LPS; ANOVA and Newman-Keuls test; $n=5-6$ per group.

(Infanger et al., 2006). Therefore, we used mice lacking nox2, the catalytic subunit of NADPH oxidase, to examine whether the increase in ROS induced by LPS was mediated by NADPH oxidase. The increase in ROS induced by LPS was not observed in nox2-null mice (Fig. 5D,E). In contrast, in iNOS-null mice the increase in ROS was not different from that of wild-type mice (Fig. $5 D, E$ ). Therefore, LPS induces ROS production in neurons and cerebral blood vessels, an effect not observed in nox2-null mice.

NADPH oxidase contributes to LPS-induced ischemic tolerance and vasoprotection

Next, we used nox2-null mice to test the hypothesis that nox2derived ROS are involved in the preconditioning induced by LPS. The infarct produced by MCA occlusion was smaller in nox2-null mice than in wild-type littermates (Walder et al., 1997; Kunz et
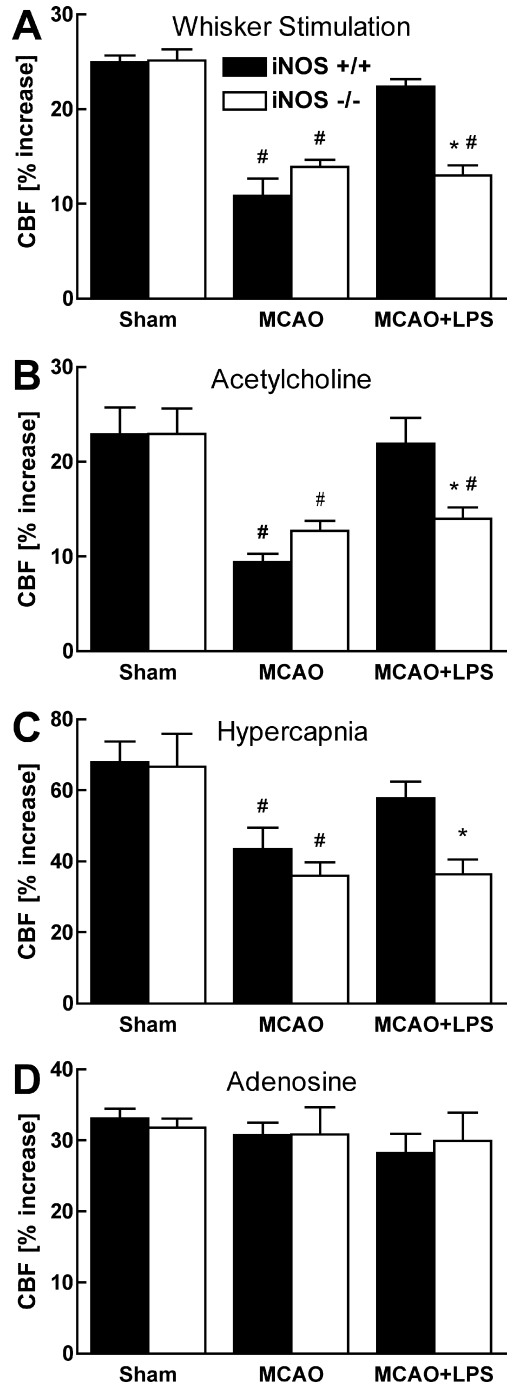

Figure 4. $A-D$, Effect of MCA occlusion (MCAO) on the increase in CBF produced by whisker stimulation $(\boldsymbol{A})$, topical superfusion with acetylcholine $(10 \mu \mathrm{M} ; \boldsymbol{B})$, hypercapnia $\left(\mathrm{pCO}_{2}=\right.$ 50-60 mmHg; ), or topical superfusion of adenosine (400 $\mu \mathrm{m} ; \boldsymbol{D})$ in wild-type mice (iNOS $+/+$ ) or iNOS $-/-$ mice with or without LPS. * $p<0.05$ compared with iNOS $+/+$; ${ }^{\#} p<0.05$ compared with sham; ANOVA and Newman-Keuls test; $n=5-6$ per group.

al., 2007), but LPS did not further reduce the infarct (vehicle, $23 \pm 7 \mathrm{~mm}^{3}$; LPS, $19 \pm 3 \mathrm{~mm}^{3} ; p>0.05 ; n=5-6$ per group). In contrast, administration of 7-NI attenuated the infarct volume by $52 \%$ (vehicle, $26 \pm 5 \mathrm{~mm}^{3} ; 7-\mathrm{NI}, 13 \pm 1 \mathrm{~mm}^{3} ; p<0.05 ; n=5$ per group), ruling out that the lack of protection by LPS was attributable to a maximally reduced infarct. In nox2-null mice, LPS failed to improve intraischemic $\mathrm{CBF}$ in regions of the ischemic territory that were spared from infarction (Fig. 6B). We then examined the effect of LPS on postischemic vascular reactivity in nox2-null mice. In contrast to wild-type mice, LPS failed to improve the postischemic attenuation in vascular reactivity in nox2null mice (Fig. 6B-D; supplemental Fig. 2, available at www. jneurosci.org as supplemental material). Therefore, NADPH oxidase is needed for LPS-induced tolerance and improved vascular reactivity.

\section{LPS preconditioning increases peroxynitrite formation in} cerebral blood vessels

The finding that both NO and ROS are needed for the tolerance induced by LPS suggests an involvement of peroxynitrite, the 


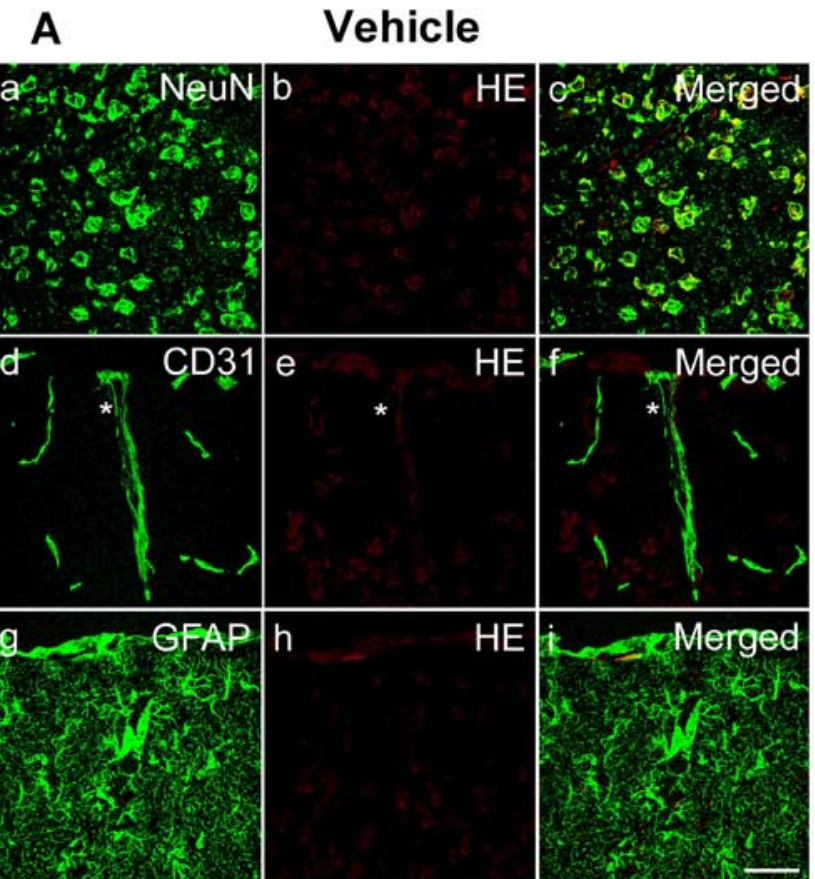

B
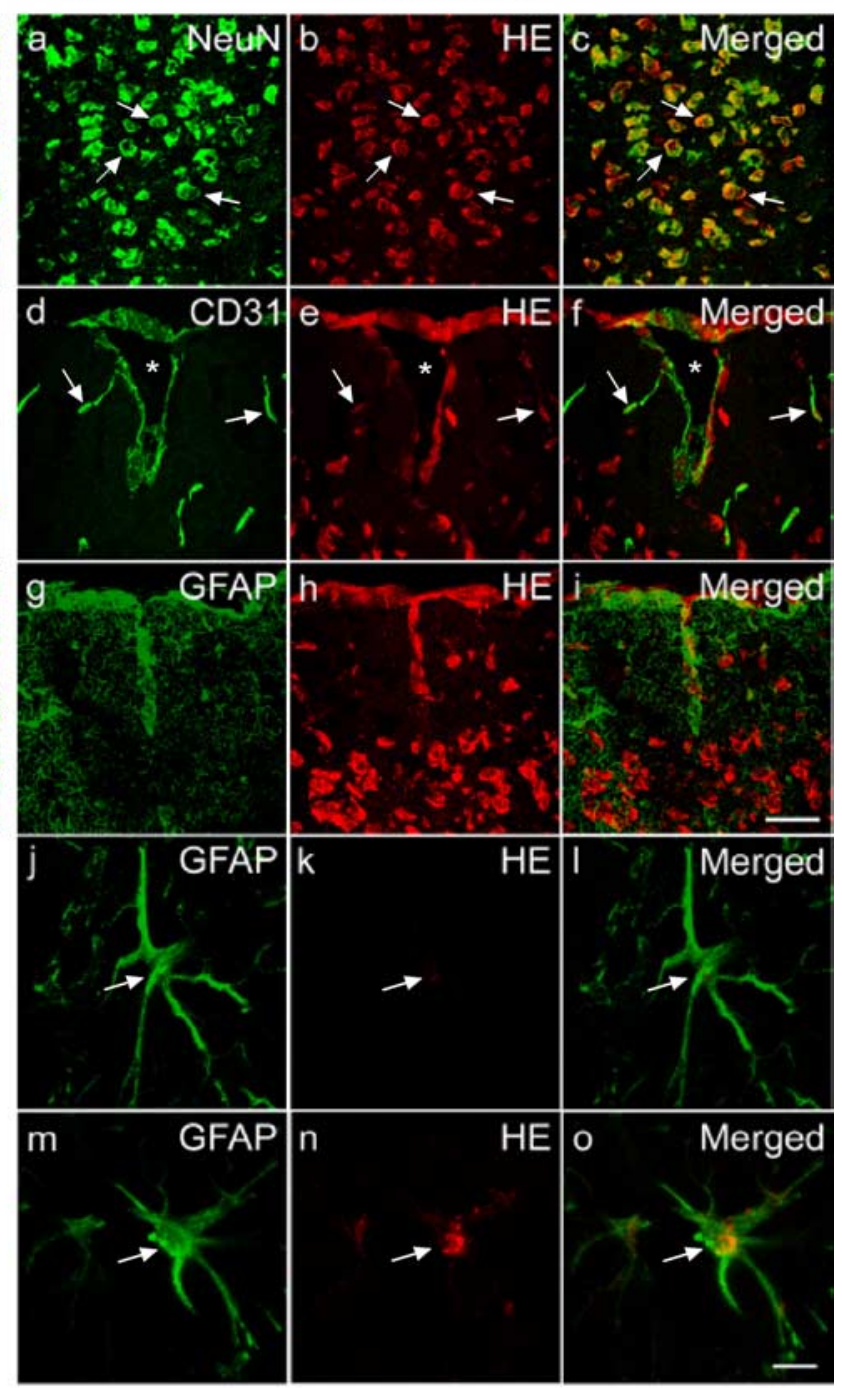

E

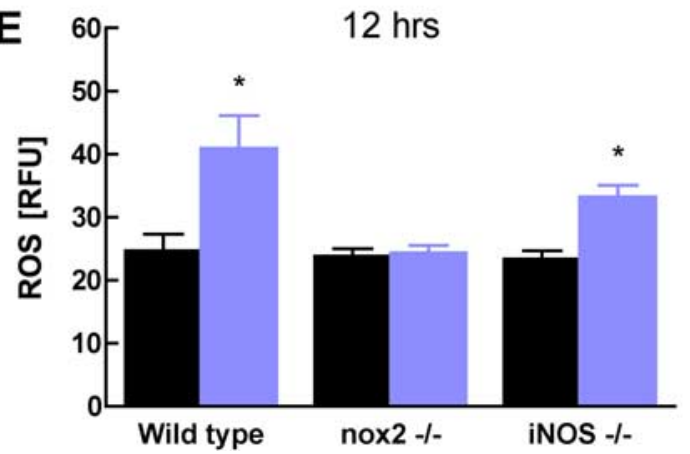

Figure 5. $\boldsymbol{A}, \mathrm{ROS}$ production in neocortex assessed by hydroethidine (HE) microfluorography in mice treated with vehicle. Brain sections of mice treated with $H E(\boldsymbol{b}, \boldsymbol{e}, \boldsymbol{h})$ were counterstained with the neuronal marker NeuN $(\boldsymbol{a}, \boldsymbol{c})$, the endothelial marker CD31 $(\boldsymbol{d}, \boldsymbol{f})$, or the astroglial marker GFAP $(\boldsymbol{g}, \boldsymbol{i})$. $\boldsymbol{d}-\boldsymbol{f}$, Asterisks indicate penetrating cortical arterioles. Scale bar, $50 \mu \mathrm{m} . \boldsymbol{B}, \mathrm{R} 0 \mathrm{~S}$ production $2 \mathrm{~h}$ after LPS in neurons $(\boldsymbol{a}-\boldsymbol{c})$, CD31-positive vascular profiles $(\boldsymbol{d}-\boldsymbol{f})$, and GFAP-labeled astrocytes $(\boldsymbol{g}-\boldsymbol{i})$. $\boldsymbol{a}-\boldsymbol{c}$, Arrows point to examples of neurons with increased ROS signal. $\boldsymbol{d}-\boldsymbol{f}$, Asterisks indicate penetrating cortical arterioles, and arrows indicate capillaries. $\boldsymbol{g}-\boldsymbol{I}$, LPS did not increase ROS production in astrocytes $(\boldsymbol{g}-\boldsymbol{i})$, shown at higher magnification in $\boldsymbol{j}-\boldsymbol{I}$ (arrows). $\boldsymbol{m} \mathbf{- o}$, In contrast, superfusion with the SOD inhibitor DDC increased astrocytic ROS production (arrows). Scale bars: $\boldsymbol{a}-\boldsymbol{i}$ (in $\boldsymbol{i}), 50 \mu \mathrm{m} ; \boldsymbol{j}-\boldsymbol{o}$ (in $\boldsymbol{o}$ ), $5 \mu \mathrm{m}$. $\boldsymbol{C}$, Time course of ROS production in vessels and brain parenchyma in mice treated with LPS. ${ }^{*} p<0.05$ compared with vehicle (Veh); ANOVA and Dunnett's test. D, ROS production in wild-type, nox2 $-/-$, or iNOS $-/-$ mice $2 \mathrm{~h}$ after LPS. ${ }^{*} p<0.05$ compared with vehicle; Student's $t$ test. $E$, ROS production $12 \mathrm{~h}$ after LPS. ${ }^{*} p<0.05$ compared with vehicle; Student's $t$ test; $n=5-7$ per group. RFU, Relative fluorescence units.

product of the reaction between $\mathrm{NO}$ and superoxide (Pacher et al., 2007). First, we used 3-NT as a nitration marker to determine whether LPS increases peroxynitrite formation in cerebral cortex. LPS increased 3-NT immunoreactivity in the cerebral cortex
(Fig. 7C). Double-label experiments with neuronal, endothelial, and astrocytic markers showed that the increase occurred in neurons and cerebral blood vessels, but not in astrocytes (Fig. $7 A, B$ ). The increase in 3-NT immunoreactivity was first observed $2 \mathrm{~h}$ 

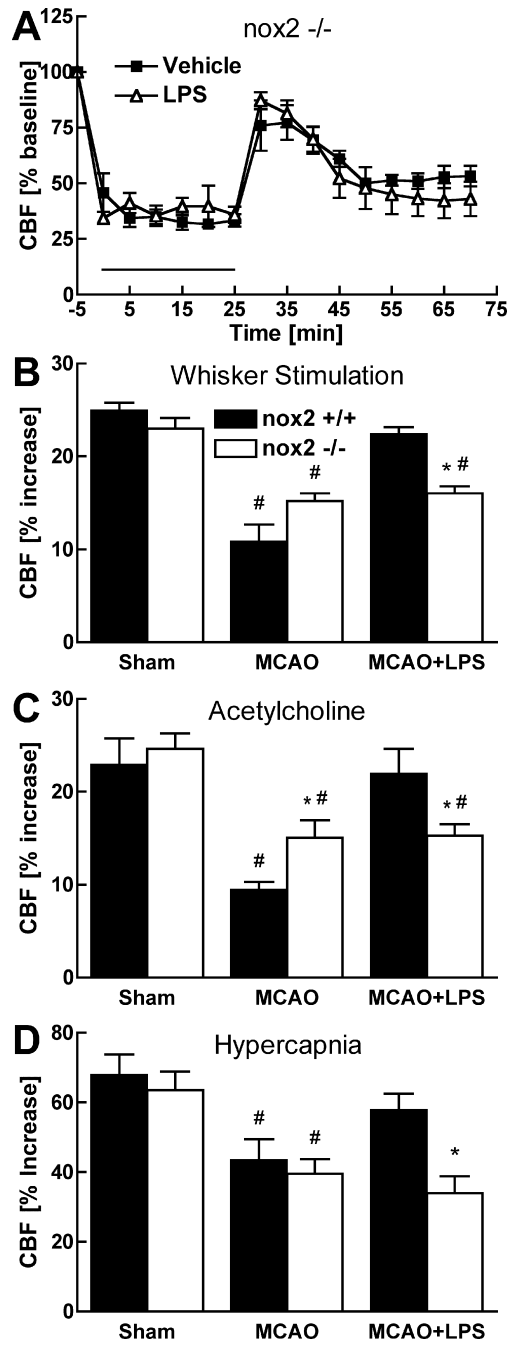

Figure 6. $A$, Effect of $L P S$ on intraischemic $C B F$ in nox2-null mice. $B-D$, Effect of MCA occlusion (MCAO) on the increase in $(B F$ produced by whisker stimulation $(B)$, acetylcholine $(10 \mu \mathrm{M}$; C), and hypercapnia $\left(\mathrm{pCO}_{2}=50-60 \mathrm{mmHg} ; \boldsymbol{D}\right)$ in wild-type mice (nox2 $+/+$ ) or nox2-/mice with or without LPS. ${ }^{*} p<0.05$ compared with nox $2+1+;{ }^{\#} p<0.05$ compared with sham; ANOVA and Newman-Keuls test; $n=5-6$ per group.

after LPS and was still present at $24 \mathrm{~h}$ (Fig. 7C). To provide evidence that peroxynitrite was responsible for the nitration, we investigated LPS-induced 3-NT immunoreactivity in iNOS or nox2-null mice. LPS-induced nitration was not observed in mice lacking iNOS or nox2 (Fig. 7D), attesting to the fact that nitration depends on iNOS-derived NO and nox2-derived ROS.

\section{Peroxynitrite is required for the ischemic tolerance and vasoprotection induced by LPS}

Finally, to provide evidence that peroxynitrite is involved in the vasoprotection and ischemic tolerance induced by LPS, we used the peroxynitrite decomposition catalyst FeTPPS (Misko et al., 1998; Salvemini et al., 1998; Li et al., 2005). To verify that FeTPPS administration reduced protein nitration, we examined its effect on 3-NT immunoreactivity. We found that FeTPPS, administered $10 \mathrm{~min}$ and $6 \mathrm{~h}$ after LPS, attenuates the increase in 3-NT immunoreactivity induced by LPS, attesting to its effectiveness in our model (supplemental Fig. $3 A-C$, available at www. jneurosci.org as supplemental material). FeTPPS by itself had no effect on the size of the infarct (Fig. $8 \mathrm{~A}$ ). However, this agent attenuated the protective effect of LPS, albeit not completely (Fig.
$8 A)$. Furthermore, FeTPPS blocked the improvement in intraischemic CBF produced by LPS (Fig. 8 B). Similarly, FeTPPS abolished the improvement in postischemic vascular dysregulation (Figs. 8C-F). Thus, FeTPPS counteracts the beneficial effects of LPS on ischemic CBF, cerebrovascular function, and infarct volume.

\section{Discussion}

We have demonstrated that the tolerance to cerebral ischemia induced by LPS is associated with an improvement in cerebral perfusion in regions of the ischemic territory that are spared from infarction. LPS counteracts the vascular dysregulation induced by cerebral ischemia and improves cerebrovascular function in the ischemic brain. These beneficial vascular effects of LPS are blocked by the iNOS inhibitor AG and are not observed in iNOSnull mice, indicating that iNOS-derived NO is involved in the response. In addition, the effects of LPS depend on ROS generated by a nox2-containing NADPH oxidase, raising the possibility that peroxynitrite, the reaction product of $\mathrm{NO}$ and superoxide, is involved in the mechanisms of the tolerance. In support of this hypothesis, LPS administration increased nitration in neurons and cerebral blood vessels. Furthermore, the peroxynitrite decomposition catalyst FeTPPS counteracted the beneficial vascular effects and the reduction in ischemic injury associated with LPS administration. These observations provide evidence that LPS-induced tolerance to ischemic injury is associated with a marked improvement of vascular function in the ischemic brain and that this effect depends on peroxynitrite formed from iNOSderived NO and nox2-derived radicals.

The findings of the present study cannot be attributed to methodological artifacts or instability of the preparation. The physiological variables of the mice, including body temperature, were carefully monitored and controlled and did not differ among the experimental groups. Although nitration can be induced by factors other than peroxynitrite, such as myeloperoxidase in the presence of nitrite and $\mathrm{H}_{2} \mathrm{O}_{2}$ (Eiserich et al., 1998; Gaut et al., 2002), this was not the case here because LPS-induced nitration depends on iNOS-derived NO and NADPH oxidasederived superoxide, pointing to the involvement of peroxynitrite. Therefore, the findings of the present study cannot result from confounding factors or artifacts of the methods used to assess ROS production or nitration.

LPS administration attenuated the CBF reduction produced by MCA occlusion in regions at risk for infarction. Ischemia produces local vascular dysregulation that impairs the ability of cerebral blood vessels to vasodilate and to draw blood from adjacent vascular territories that are perfused normally (Date and Hossmann, 1984; Mayhan et al., 1988) (for review, see Iadecola, 1998). Such vasoparalysis impairs collateral flow and lowers CBF toward the threshold for infarction (Iadecola, 1998). Our data indicate that LPS improves cerebral perfusion in these "watershed" regions that are rescued from infarction. Several lines of evidence suggest that the improvement of CBF is causally linked to the improved tissue outcome. First, it is well established that interventions that improve $\mathrm{CBF}$ in the ischemic territory, such as NO donors, ameliorate the tissue damage (Morikawa et al., 1994; Zhang et al., 1994). It is therefore likely that the CBF improvement produced by LPS administration has similar beneficial consequences. Second, the improvement in CBF is observed immediately after arterial occlusion, well before the tissue damage develops. Therefore, the reduction in brain damage could not influence ischemic flow, because the lesion was not yet present. Third, we have shown here that LPS protects cerebral blood ves- 
A
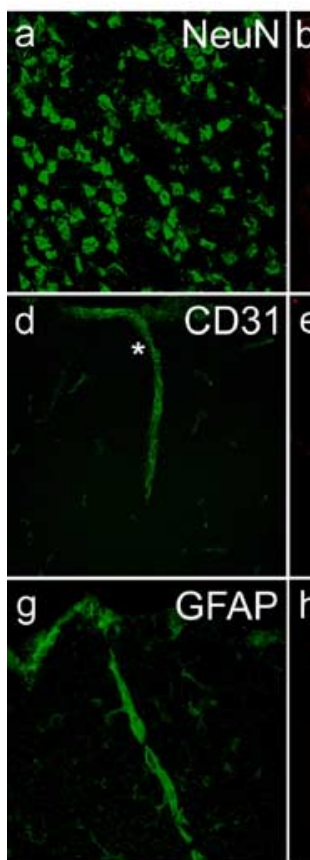

C

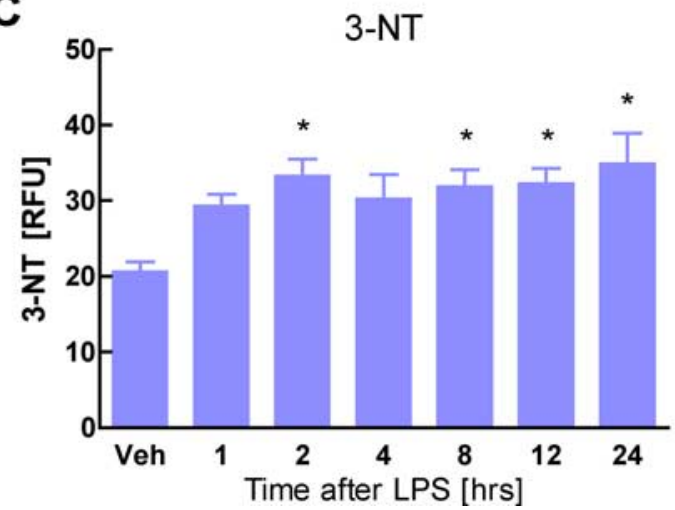

3-NT
B

LPS 24hrs
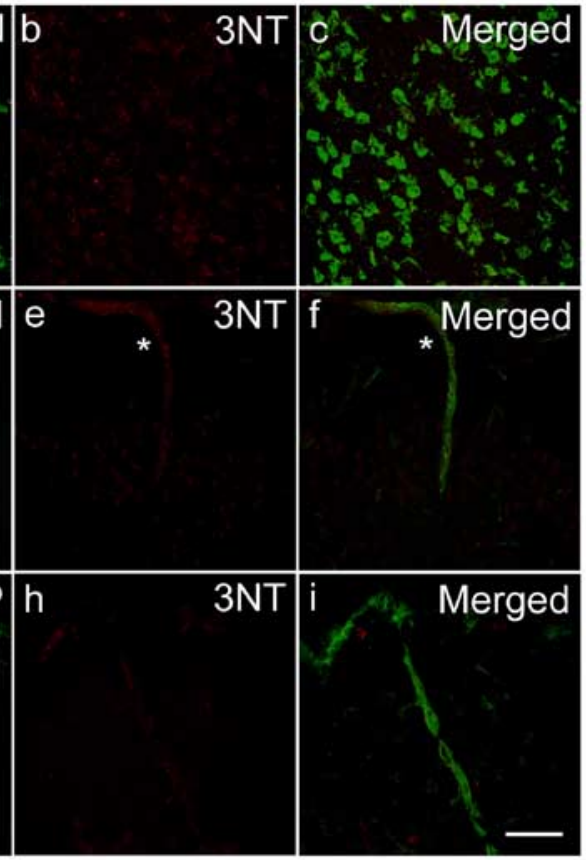

D
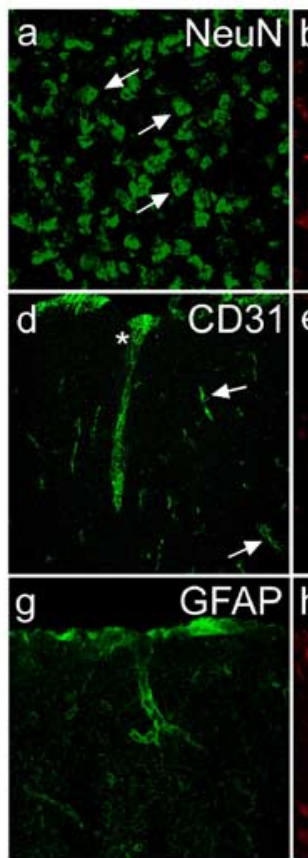
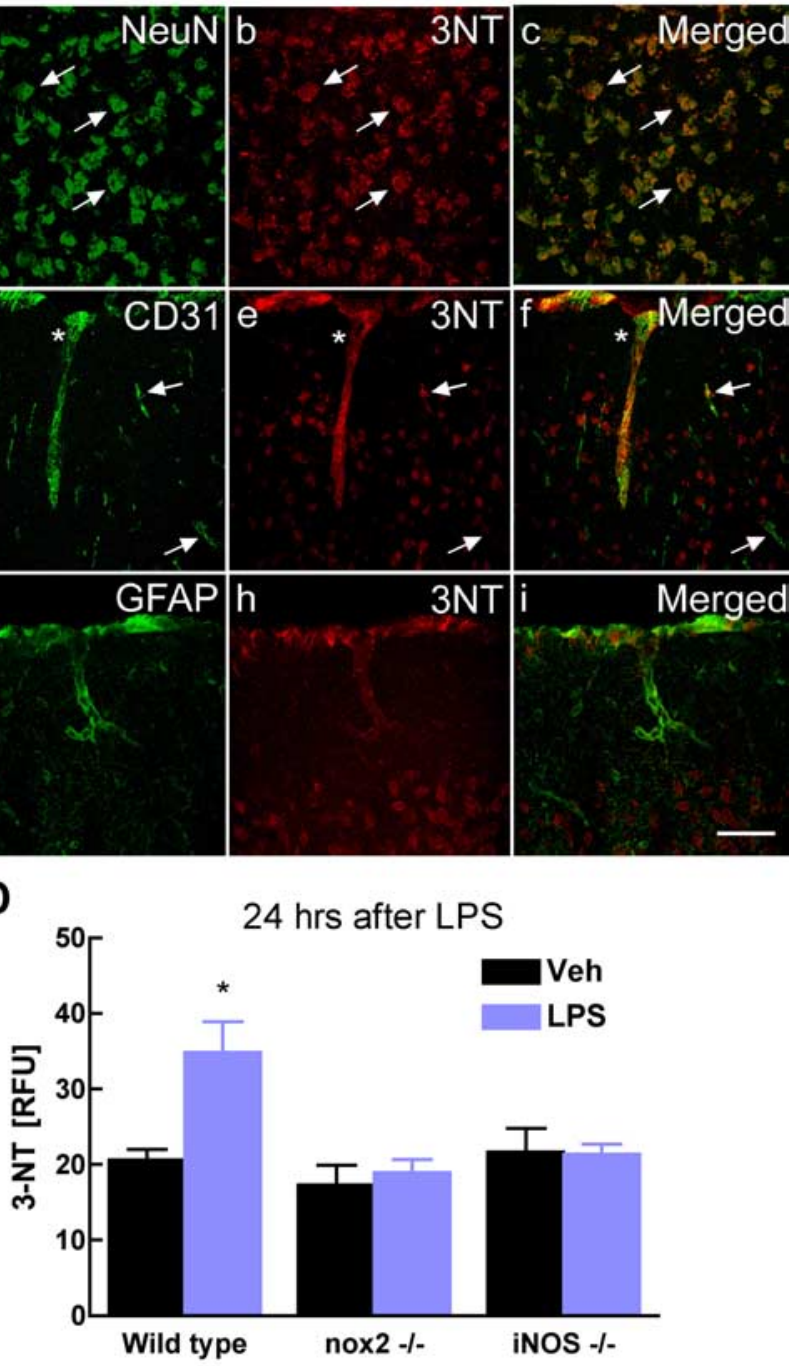

Figure 7. $\boldsymbol{A}, 3-N T$ immunoreactivity in the neocortex of vehicle-treated mice. Sections were also processed for NeuN ( $\boldsymbol{a}-\boldsymbol{c}), \mathrm{CD} 31(\boldsymbol{d}-\boldsymbol{f})$, or GFAP $(\boldsymbol{g}-\boldsymbol{i})$ immunoreactivity. $\boldsymbol{d}-\boldsymbol{f}$, Asterisks indicate a penetrating arteriole. $\boldsymbol{B}, 3-N T$ immunoreactivity $24 \mathrm{~h}$ after LPS. $\boldsymbol{a}-\boldsymbol{f}, 3-\mathrm{NT}$ immunoreactivity is increased especially in neurons ( $\boldsymbol{a}-\boldsymbol{c}$; arrows) and vascular profiles (d-f; arrows). $\boldsymbol{g}-\boldsymbol{i}$, Increased 3-NT immunoreactivity was not observed in astrocytes. Scale bars: $\boldsymbol{A}, \boldsymbol{B}, \boldsymbol{a}-\boldsymbol{c}, \boldsymbol{g}-\boldsymbol{i}$ (in $\boldsymbol{i}), 50 \mu \mathrm{m} ; \boldsymbol{d}-\boldsymbol{f}$ (in $\boldsymbol{i}), 80 \mu \mathrm{m}$. $\boldsymbol{C}$, Time course of $3-N T$ immunoreactivity in mice treated with LPS. ${ }^{*} p<0.05$ compared with vehicle; ANOVA and Dunnett's test; $n=6$ per group. D, 3-NT immunoreactivity $24 \mathrm{~h}$ after LPS in wild-type, iNOS $-/-$, or nox2 $-/-$ mice. ${ }^{*} p<0.05$ compared with vehicle; Student's $t$ test; $n=5-6$ per group. RFU, Relative fluorescence units; Veh, vehicle.

sels from the dysfunction induced by cerebral ischemia. It remains to be defined whether LPS improves intraischemic cerebral perfusion also by elevating resting CBF. Thus, our data indicate that the improvement of ischemic CBF results from direct effects of LPS on cerebrovascular function and not from indirect effects secondary to the reduction in tissue damage.

It is of interest that LPS ameliorates the increase in CBF initiated by the endothelium-dependent vasodilator $\mathrm{ACh}$, a response mediated by NO released from endothelial cells (Faraci et al., 1998; Girouard et al., 2007). This observation indicates that LPS is able to directly influence responses mediated by mechanisms intrinsic to cerebral blood vessels. Consistent with this view, systemic administration of low doses of LPS $(0.3-0.5 \mathrm{mg} / \mathrm{kg}) \mathrm{im}-$ proves endothelium-dependent relaxation in the isolated aorta (Pu et al., 1999) and MCA (Bastide et al., 2003). It must be noted that higher doses of LPS ( $5 \mathrm{mg} / \mathrm{kg}$ ) impair endothelial function in cerebral blood vessels, an effect mediated by vascular ROS production (Didion et al., 2004). Therefore, LPS can be either bene- ficial or deleterious to endothelial function depending on the dose administered. In preconditioning, the vascular effects of low doses of LPS are beneficial and protect the vessels from the dysfunction caused by cerebral ischemia.

Preconditioning stimuli induce the expression of neuroprotective genes, improve mitochondrial function, and lead to neurotransmitter and receptor changes that increase the resistance of the neurons and glia to ischemic injury (Dirnagl et al., 2003; Gidday, 2006). Our data suggest that preconditioning, in addition to protecting brain cells, also protects cerebral blood vessels from the deleterious effects of ischemia and improves their function. These findings add another dimension to the effector mechanisms of the tolerance and suggest that LPS exerts both neuroprotective and vasoprotective actions on the ischemic brain.

This conclusion is not surprising considering the close relationships that exist among neurons, glia, and cerebral blood vessels (Iadecola, 2004). In the normal state, neurons, glia and cerebrovascular cells work in concert to assure that the energy 

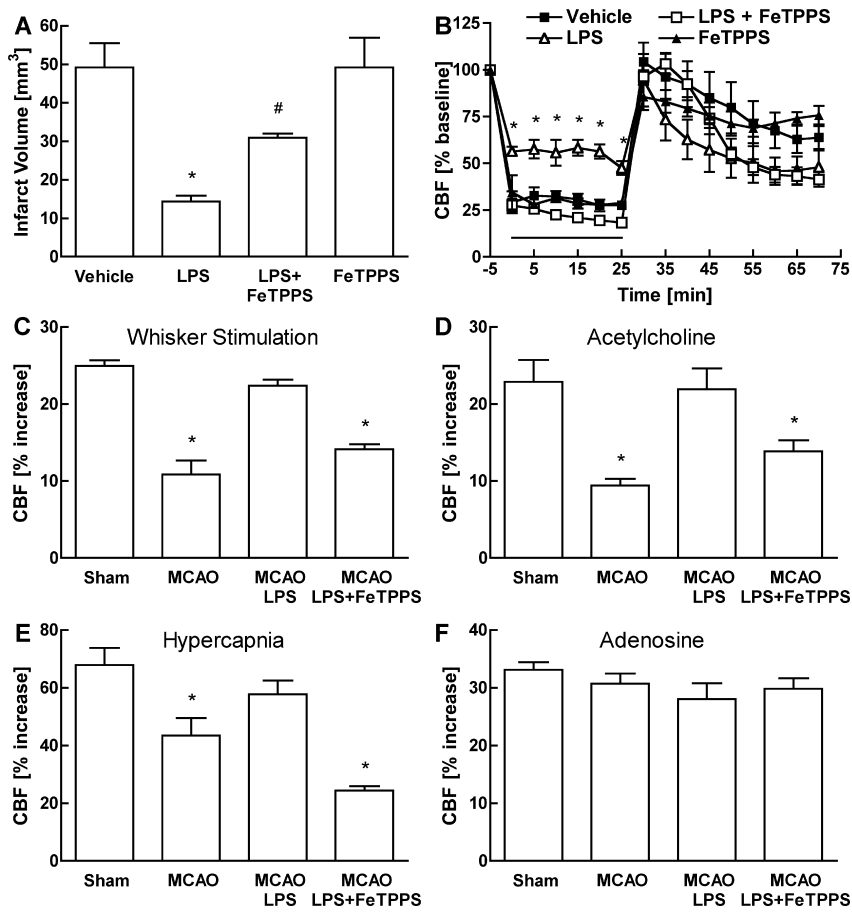

Figure 8. $\quad A$, Effect of LPS on infarct volume in mice treated with vehicle, LPS, LPS plus FeTPPS, or FeTPPS alone. ${ }^{*} p<0.05$ compared with vehicle; ${ }^{\#} p<0.05$ compared with vehicle and LPS; ANOVA and Newman-Keuls test; $n=6-7$ per group. $\boldsymbol{B}$, Effect of LPS on intraischemic CBF in the groups of mice presented in $\boldsymbol{A} .{ }^{*} p<0.05$ compared with vehicle, LPS plus FeTPPS, and FeTPPS; ANOVA and Newman-Keuls test; $n=5-6$ per group. $C-F$, Effect of MCA occlusion (MCAO) on the increase in $(B F$ produced by whisker stimulation $(\boldsymbol{C})$, acetylcholine $(10 \mu \mathrm{m} ; \boldsymbol{D})$, hypercapnia $\left(\mathrm{pCO}_{2}=50-60 \mathrm{mmHg} ; \boldsymbol{F}\right)$, or adenosine $(400 \mu \mathrm{m} ; \boldsymbol{F})$ in mice treated with vehicle, LPS, or LPS plus FeTPPS. ${ }^{*} p<0.05$ compared with sham and MCAO plus LPS; ANOVA and Newman-Keuls test; $n=5-6$ per group.

demands of the brain are matched to an adequate delivery of energy substrates (Iadecola, 2004). In pathological states, damage to one cell type leads to alterations in the other cell types as well (del Zoppo and Mabuchi, 2003; Iadecola, 2004). We have demonstrated here that the vascular disruption involves not only responses mediated by neural activity, such as functional hyperemia, but also responses mediated by endothelial cells (i.e., the increase in $\mathrm{CBF}$ produced by $\mathrm{ACh}$ ). Importantly, the CBF response to the smooth muscle relaxant adenosine was not altered, indicating that the attenuation of the $\mathrm{CBF}$ responses to neural activity, hypercapnia, and $\mathrm{ACh}$ was not a consequence of nonspecific vasoparalysis or mechanical failure of smooth muscle cells. In contrast to adenosine, the $\mathrm{CBF}$ response to hypercapnia was attenuated by cerebral ischemia. Although hypercapnia can directly relax cerebrovascular muscles through the associated changes in $\mathrm{pH}$ (Kontos et al., 1977a,b), neurogenic factors are also thought to contribute to the response. For example, a critical level of neuronal NO/cGMP is required for the expression of the hypercapnic vasodilation (Irikura et al., 1994; Iadecola and Zhang, 1996). It is likely that such a neurogenic component of the CBF response is altered by ischemia. Therefore, ischemia produces dysfunction of key intrinsic cerebrovascular regulatory processes that parallel the neuronal dysfunction. The protective effect of preconditioning targets both the neuronal and vascular components of the damage, resulting in a remarkable reduction in the size of the infarct.

Our data suggest that peroxynitrite is involved in the protective effect of LPS. Peroxynitrite can have both beneficial and deleterious effects depending on the amount generated. At relatively high concentrations (micromolar), peroxynitrite can induce oxidative and nitrosative damage in brain and blood vessels and leads to cerebrovascular dysfunction (Maneen and Cipolla, 2007). However, at low concentrations (nanomolar), peroxynitrite activates protective stress pathways (Akt and MAP kinase), induces vasodilation, and inhibits leukocyte adhesion (Wei et al., 1996; Lefer et al., 1997; Nossuli et al., 1997; Klotz et al., 2002; Li et al., 2004). Therefore, low concentrations of peroxynitrite, such as those produced in LPS preconditioning, can be beneficial to the ischemic brain. In the peripheral circulation, peroxynitrite improves endothelial function, protects the myocardium from injury, and can act as a preconditioning agent (Lefer et al., 1997; Nossuli et al., 1997; Altug et al., 2000). In the CNS, peroxynitrite is involved in LPS preconditioning against excitotoxic brain lesions (Kawano et al., 2007). However, the factors controlling the switch between beneficial and deleterious actions of peroxynitrite need to be defined. Regardless of the mechanisms of the effect, the present results suggest that peroxynitrite contributes to the brain protection afforded by LPS also by preserving cerebrovascular function.

Other NOS isoforms have also been implicated in ischemic tolerance (Gidday, 2006). For example, Atochin et al. (2003) have provided evidence that the endothelial (eNOS) and neuronal (nNOS) isoforms of NOS participate in the early preconditioning induced by transient cerebral ischemia, whereas eNOS may be involved in hypoxic preconditioning in a neonatal model of cerebral hypoxic-ischemic injury (Gidday et al., 1999). We recently found that nNOS and eNOS, but not iNOS, play a role in the early preconditioning induced by LPS (Orio et al., 2007). These data suggest that the constitutive isoforms of NOS participate in the early preconditioning induced by LPS. In delayed LPS preconditioning, iNOS expression is likely to be induced by activation of nuclear factor $\kappa \mathrm{B}$, either directly by LPS acting on Toll-like receptor 4 or indirectly through the release of tumor necrosis factor- $\alpha$ or other cytokines (Lin and Yeh, 2005; Kanzler et al., 2007).

In conclusion, we have demonstrated that LPS preconditioning reduces ischemic brain injury and improves ischemic CBF. LPS also counteracts the deleterious effect of ischemia on vascular and neurogenic mechanisms regulating the cerebral circulation. The neuroprotective and vasoprotective effects of LPS are mediated by peroxynitrite produced by iNOS-derived NO and nox2-derived superoxide. The data provide direct evidence that vascular factors play a key role in the remarkable protective effects of LPS and suggest that the endogenous mechanisms by which the brain protects itself rely on preserving both brain cells and cerebral blood vessels. Accordingly, optimal treatments for ischemic stroke should target not only neurons and glia, but also cerebral blood vessels.

\section{References}

Altug S, Demiryurek AT, Kane KA, Kanzik I (2000) Evidence for the involvement of peroxynitrite in ischaemic preconditioning in rat isolated hearts. Br J Pharmacol 130:125-131.

Atochin DN, Clark J, Demchenko IT, Moskowitz MA, Huang PL (2003) Rapid cerebral ischemic preconditioning in mice deficient in endothelial and neuronal nitric oxide synthases. Stroke 34:1299-1303.

Bastide M, Gele P, Petrault O, Pu Q, Caliez A, Robin E, Deplanque D, Duriez P, Bordet R (2003) Delayed cerebrovascular protective effect of lipopolysaccharide in parallel to brain ischemic tolerance. J Cereb Blood Flow Metab 23:399-405.

Borsello T, Clarke PG, Hirt L, Vercelli A, Repici M, Schorderet DF, Bogousslavsky J, Bonny C (2003) A peptide inhibitor of c-Jun N-terminal kinase protects against excitotoxicity and cerebral ischemia. Nat Med 9:1180-1186. 
Boutin H, LeFeuvre RA, Horai R, Asano M, Iwakura Y, Rothwell NJ (2001) Role of IL- $1 \alpha$ and IL- $1 \beta$ in ischemic brain damage. J Neurosci 21:5528-5534.

Cho S, Park EM, Febbraio M, Anrather J, Park L, Racchumi G, Silverstein RL, Iadecola C (2005a) The class B scavenger receptor CD36 mediates free radical production and tissue injury in cerebral ischemia. J Neurosci 25:2504-2512.

Cho S, Park EM, Zhou P, Frys K, Ross ME, Iadecola C (2005b) Obligatory role of inducible nitric oxide synthase in ischemic preconditioning. J Cereb Blood Flow Metab 25:493-501.

Date H, Hossmann KA (1984) Effect of vasodilating drugs on intracortical and extracortical vascular resistance following middle cerebral artery occlusion in cats. Ann Neurol 16:330-336.

Dawson DA, Furuya K, Gotoh J, Nakao Y, Hallenbeck JM (1999) Cerebrovascular hemodynamics and ischemic tolerance: lipopolysaccharideinduced resistance to focal cerebral ischemia is not due to changes in severity of the initial ischemic insult, but is associated with preservation of microvascular perfusion. J Cereb Blood Flow Metab 19:616-623.

Dawson TM (2002) Preconditioning-mediated neuroprotection through erythropoietin? Lancet 359:96-97.

del Zoppo GJ, Mabuchi T (2003) Cerebral microvessel responses to focal ischemia. J Cereb Blood Flow Metab 23:879-894.

Didion SP, Kinzenbaw DA, Fegan PE, Didion LA, Faraci FM (2004) Overexpression of CuZn-SOD prevents lipopolysaccharide-induced endothelial dysfunction. Stroke 35:1963-1967.

Dirnagl U, Simon RP, Hallenbeck JM (2003) Ischemic tolerance and endogenous neuroprotection. Trends Neurosci 26:248-254.

Eiserich JP, Hristova M, Cross CE, Jones AD, Freeman BA, Halliwell B, van der Vliet A (1998) Formation of nitric oxide-derived inflammatory oxidants by myeloperoxidase in neutrophils. Nature 391:393-397.

Faraci FM, Sigmund CD, Shesely EG, Maeda N, Heistad DD (1998) Responses of carotid artery in mice deficient in expression of the gene for endothelial NO synthase. Am J Physiol 274:H564-H570.

Forster C, Clark HB, Ross ME, Iadecola C (1999) Inducible nitric oxide synthase expression in human cerebral infarcts. Acta Neuropathol (Berl) 97:215-220.

Furuya K, Zhu L, Kawahara N, Abe O, Kirino T (2005) Differences in infarct evolution between lipopolysaccharide-induced tolerant and nontolerant conditions to focal cerebral ischemia. J Neurosurg 103:715-723.

Gaut JP, Byun J, Tran HD, Lauber WM, Carroll JA, Hotchkiss RS, Belaaouaj A, Heinecke JW (2002) Myeloperoxidase produces nitrating oxidants in vivo. J Clin Invest 109:1311-1319.

Gidday JM (2006) Cerebral preconditioning and ischaemic tolerance. Nat Rev Neurosci 7:437-448.

Gidday JM, Shah AR, Maceren RG, Wang Q, Pelligrino DA, Holtzman DM, Park TS (1999) Nitric oxide mediates cerebral ischemic tolerance in a neonatal rat model of hypoxic preconditioning. J Cereb Blood Flow Metab 19:331-340.

Girouard H, Park L, Anrather J, Zhou P, Iadecola C (2007) Cerebrovascular nitrosative stress mediates neurovascular and endothelial dysfunction induced by angiotensin II. Arterioscler Thromb Vasc Biol 27:303-309.

Hoyte LC, Papadakis M, Barber PA, Buchan AM (2006) Improved regional cerebral blood flow is important for the protection seen in a mouse model of late phase ischemic preconditioning. Brain Res 1121:231-237.

Iadecola C (1992) Nitric oxide participates in the cerebrovasodilation elicited from cerebellar fastigial nucleus. Am J Physiol 263:R1156-R1161.

Iadecola C (1998) Cerebral circulatory dysregulation in ischemia. In: Cerebrovascular disease. Pathophysiology, diagnosis, and management (Ginsberg MD, Bogousslavsky J, eds), pp 319-331. Malden, MA: Blackwell Science.

Iadecola C (2004) Neurovascular regulation in the normal brain and in Alzheimer's disease. Nat Rev Neurosci 5:347-360.

Iadecola C, Zhang F (1996) Permissive and obligatory roles of NO in cerebrovascular responses to hypercapnia and acetylcholine. Am J Physiol 271:R990-R1001.

Infanger DW, Sharma RV, Davisson RL (2006) NADPH oxidases of the brain: distribution, regulation, and function. Antioxid Redox Signal 8:1583-1596.

Irikura K, Maynard KI, Lee WS, Moskowitz MA (1994) L-NNA decreases cortical hyperemia and brain cGMP levels following $\mathrm{CO}_{2}$ inhalation in Sprague-Dawley rats. Am J Physiol 267:H837-H843.

Kanzler H, Barrat FJ, Hessel EM, Coffman RL (2007) Therapeutic targeting of innate immunity with Toll-like receptor agonists and antagonists. Nat Med 13:552-559.

Kapinya KJ, Lowl D, Futterer C, Maurer M, Waschke KF, Isaev NK, Dirnagl U (2002) Tolerance against ischemic neuronal injury can be induced by volatile anesthetics and is inducible NO synthase dependent. Stroke 33:1889-1898.

Kawano T, Kunz A, Abe T, Girouard H, Anrather J, Zhou P, Iadecola C (2007) iNOS-derived NO and nox2-derived superoxide confer tolerance to excitotoxic brain injury through peroxynitrite. J Cereb Blood Flow Metab, in press.

Kirino T (2002) Ischemic tolerance. J Cereb Blood Flow Metab 22:1283-1296.

Klotz LO, Schroeder P, Sies H (2002) Peroxynitrite signaling: receptor tyrosine kinases and activation of stress-responsive pathways. Free Radic Biol Med 33:737-743.

Kondo T, Reaume AG, Huang TT, Carlson E, Murakami K, Chen SF, Hoffman EK, Scott RW, Epstein CJ, Chan PH (1997) Reduction of CuZnsuperoxide dismutase activity exacerbates neuronal cell injury and edema formation after transient focal cerebral ischemia. J Neurosci 17:4180-4189.

Kontos HA, Wei EP, Raper AJ, Patterson Jr JL (1977a) Local mechanism of $\mathrm{CO}_{2}$ action of cat pial arterioles. Stroke 8:226-229.

Kontos HA, Raper AJ, Patterson JL (1977b) Analysis of vasoactivity of local $\mathrm{pH}, \mathrm{PCO}_{2}$ and bicarbonate on pial vessels. Stroke 8:358-360.

Kunz A, Anrather J, Zhou P, Orio M, Iadecola C (2007) Cyclooxygenase-2 does not contribute to postischemic production of reactive oxygen species. J Cereb Blood Flow Metab 27:545-551.

Lefer DJ, Scalia R, Campbell B, Nossuli T, Hayward R, Salamon M, Grayson J, Lefer AM (1997) Peroxynitrite inhibits leukocyte-endothelial cell interactions and protects against ischemia-reperfusion injury in rats. J Clin Invest 99:684-691.

Li J, Li W, Altura BT, Altura BM (2004) Peroxynitrite-induced relaxation in isolated canine cerebral arteries and mechanisms of action. Toxicol Appl Pharmacol 196:176-182.

Li J, Baud O, Vartanian T, Volpe JJ, Rosenberg PA (2005) Peroxynitrite generated by inducible nitric oxide synthase and NADPH oxidase mediates microglial toxicity to oligodendrocytes. Proc Natl Acad Sci USA 102:9936-9941.

Lin TN, He YY, Wu G, Khan M, Hsu CY (1993) Effect of brain edema on infarct volume in a focal cerebral ischemia model in rats. Stroke 24:117-121.

Lin WJ, Yeh WC (2005) Implication of Toll-like receptor and tumor necrosis factor alpha signaling in septic shock. Shock 24:206-209.

Liu J, Narasimhan P, Yu F, Chan PH (2005) Neuroprotection by hypoxic preconditioning involves oxidative stress-mediated expression of hypoxia-inducible factor and erythropoietin. Stroke 36:1264-1269.

MacMicking JD, Nathan C, Hom G, Chartrain N, Fletcher DS, Trumbauer M, Stevens K, Xie Q-w, Sokol K, Hutchinson N, Chen H, Mudget JS (1995) Altered responses to bacterial infection and endotoxic shock in mice lacking inducible nitric oxide synthase. Cell 81:641-650.

Maneen MJ, Cipolla MJ (2007) Peroxynitrite diminishes myogenic tone in cerebral arteries: role of nitrotyrosine and F-actin. Am J Physiol Heart Circ Physiol 292:H1042-H1050.

Marchal G, Young AR, Baron JC (1999) Early postischemic hyperperfusion: pathophysiologic insights from positron emission tomography. J Cereb Blood Flow Metab 19:467-482.

Mayhan WG, Amundsen SM, Faraci FM, Heistad DD (1988) Responses of cerebral arteries after ischemia and reperfusion in cats. Am J Physiol 255:H879-H884.

Misko TP, Highkin MK, Veenhuizen AW, Manning PT, Stern MK, Currie MG, Salvemini D (1998) Characterization of the cytoprotective action of peroxynitrite decomposition catalysts. J Biol Chem 273:15646-15653.

Morikawa E, Moskowitz MA, Huang Z, Yoshida T, Irikura K, Dalkara T (1994) L-arginine infusion promotes nitric oxide-dependent vasodilation, increases regional cerebral blood flow, and reduces infarction volume in the rat. Stroke 25:429-435.

Nakamura H, Katsumata T, Nishiyama Y, Otori T, Katsura K, Katayama Y (2006) Effect of ischemic preconditioning on cerebral blood flow after subsequent lethal ischemia in gerbils. Life Sci 78:1713-1719.

Nossuli TO, Hayward R, Scalia R, Lefer AM (1997) Peroxynitrite reduces myocardial infarct size and preserves coronary endothelium after ischemia and reperfusion in cats. Circulation 96:2317-2324. 
Orio M, Kunz A, Kawano T, Anrather J, Zhou P, Iadecola C (2007) Lipopolysaccharide induces early tolerance to excitotoxicity via nitric oxide and cGMP. Stroke, in press.

Pacher P, Beckman JS, Liaudet L (2007) Nitric oxide and peroxynitrite in health and disease. Physiol Rev 87:315-424.

Park EM, Cho S, Frys K, Racchumi G, Zhou P, Anrather J, Iadecola C (2004) Interaction between inducible nitric oxide synthase and poly(ADPribose) polymerase in focal ischemic brain injury. Stroke 35:2896-2901.

Park L, Anrather J, Zhou P, Frys K, Pitstick R, Younkin S, Carlson GA, Iadecola C (2005) NADPH-oxidase-derived reactive oxygen species mediate the cerebrovascular dysfunction induced by the amyloid $\beta$ peptide. J Neurosci 25:1769-1777.

Phillis JW (2004) Adenosine and adenine nucleotides as regulators of cerebral blood flow: roles of acidosis, cell swelling, and KATP channels. Crit Rev Neurobiol 16:237-270.

Plesnila N, Zinkel S, Le DA, Amin-Hanjani S, Wu Y, Qiu J, Chiarugi A, Thomas SS, Kohane DS, Korsmeyer SJ, Moskowitz MA (2001) BID mediates neuronal cell death after oxygen/glucose deprivation and focal cerebral ischemia. Proc Natl Acad Sci USA 98:15318-15323.

Pollock JD, Williams DA, Gifford MA, Li LL, Du X, Fisherman J, Orkin SH, Doerschuk CM, Dinauer MC (1995) Mouse model of X-linked chronic granulomatous disease, an inherited defect in phagocyte superoxide production. Nat Genet 9:202-209.

Pu Q, Bordet R, Robin E, Puisieux F, Vallet B, Dupuis B (1999) Low dose of lipopolysaccharide induces a delayed enhanced nitric oxide-mediated relaxation in rat aorta. Eur J Pharmacol 377:209-214.
Robinson KM, Janes MS, Pehar M, Monette JS, Ross MF, Hagen TM, Murphy MP, Beckman JS (2006) Selective fluorescent imaging of superoxide in vivo using ethidium-based probes. Proc Natl Acad Sci USA 103:15038-15043.

Rothe G, Valet G (1990) Flow cytometric analysis of respiratory burst activity in phagocytes with hydroethidine and $2^{\prime}, 7^{\prime}$-dichlorofluorescin. J Leukoc Biol 47:440-448.

Salvemini D, Wang ZQ, Stern MK, Currie MG, Misko TP (1998) Peroxynitrite decomposition catalysts: therapeutics for peroxynitrite-mediated pathology. Proc Natl Acad Sci USA 95:2659-2663.

Walder CE, Green SP, Darbonne WC, Mathias J, Rae J, Dinauer MC, Curnutte JT, Thomas GR (1997) Ischemic stroke injury is reduced in mice lacking a functional NADPH oxidase. Stroke 28:2252-2258.

Wei EP, Kontos HA, Beckman JS (1996) Mechanisms of cerebral vasodilation by superoxide, hydrogen peroxide, and peroxynitrite. Am J Physiol 271:H1262-H1266.

Zhang F, Iadecola C (1994) Infarct measurement methodology. J Cereb Blood Flow Metab 14:697-698.

Zhang F, White JG, Iadecola C (1994) Nitric oxide donors increase blood flow and reduce brain damage in focal ischemia: evidence that nitric oxide is beneficial in the early stages of cerebral ischemia. J Cereb Blood Flow Metab 14:217-226.

Zhao L, Nowak Jr TS (2006) CBF changes associated with focal ischemic preconditioning in the spontaneously hypertensive rat. J Cereb Blood Flow Metab 26:1128-1140. 